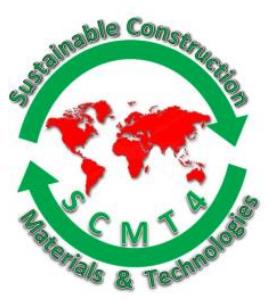

SCMT4

Las Vegas, USA, August 7-11, 2016

\title{
Residual Mechanical Properties of Fire Exposed GFRP Reinforcement in Concrete Elements
}

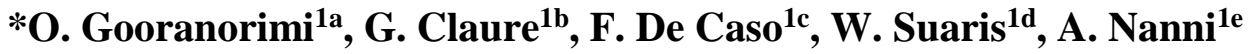 \\ ${ }^{1}$ Dept., Civil, Architectural and Environmental Engineering, University of Miami, 1251 Memorial Drive, \\ Coral Gables, 33146, Florida, USA. \\ ${ }^{1 a}$ Email: <o.gooranorimi@umiami.edu>, ${ }^{1 b}$ Email: $\langle$ g.claure@umiami.edu>, \\ ${ }^{1 c}$ Email $:<$ f.decasoybasalo@umiami.edu $\rangle,{ }^{1 d}$ Email: $\langle$ wsuaris@miami.edu $\rangle$, \\ ${ }^{1 e}$ Email:<nanni@miami.edu>.
}

\begin{abstract}
Technologies developed over the last two decades have facilitated the use of glass fiber reinforced polymer (GFRP) composites as internal reinforcement bars (rebars) for concrete structures; providing an alternative to steel reinforcement due to significant advantages such as magnetic transparency and most importantly, corrosion resistance leading to a sustainable and durable solution for the built infrastructure. Composites reduce the long-term maintenance costs over the lifetime of a structure, especially in reinforced concrete (RC) elements in corrosive environments such as coastal constructions. However, this technology has not been embraced in buildings due to concerns regarding fire resistance of RC-GFRP elements, where bondto-concrete concerns are raised due to different available surface enhancement solutions in GFRP rebars. In order to accelerate the integration of sustainable construction materials in RC buildings, the residual strength of fire exposed RC-GFRP slabs is studied. To this end, RC-GFRP slabs with two significantly different surface features, namely deformed lugs comparable to steel rebar and sand coated, were exposed to a combined fire and sustained three-point bending service load for two hours. Upon completion of the test, the residual slab strength was tested by conducting a static test. GFRP bars were then extracted from the concrete evaluate the residual mechanical properties including shear strength, glass transition temperature, and visual analysis using Scanning Electron Microscopy (SEM). Overall the results for both types of rebars showed that the GFRP-RC slabs did not lose structural integrity after the fire. Additionally, fire exposed GFRP rebars showed equivalent properties to unexposed rebars. The results may provide necessary information to accelerate the integration of this sustainable technology into the built infrastructure.
\end{abstract}

\section{INTRODUCTION}

Fiber reinforced polymer (FRP) bars are emerging as suitable alternatives for black steel and epoxy-coated steel rebars in reinforced concrete (RC) especially in applications where corrosion resistance, electromagnetic transparency, and ease of demolishing in temporary applications are required [Nanni, et al., 2014]. Use of FRP materials leads to more durable and sustainable structures resulting in reduced repair, rehabilitation, and long-term maintenance costs. The use of glass FRP (GFRP) rebars as shear and flexural 
reinforcements in RC elements in highly corrosive environments such as bridge decks and marine structures has increased. Several organizations including the American Concrete Institute (ACI) Committee 440 and the American society of international association for testing and materials (ASTM International) have provided documents including test methods, specifications, and guidelines for the GFRP reinforcing technology. The application of GFRP in structures with possible fire scenarios is limited since GFRP materials may be susceptible to deterioration of mechanical and bond properties at elevated temperature. Provision for adequate fire resistance of GFRP-RC elements is a fundamental design requirement to ensure structural integrity for an adequate period of time [Nigro, et al., 2011]. There is a lack of reliable data regarding the behavior of GFRP-RC under fire. Moreover, there is no proper structural design code for fire exposure except the Canadian code [CSA S806, 2012] that provides a design procedure based on a study by Kodur and Baingo [1998]. In the case of steel, the design for fire resistance is based on avoiding a threshold temperature defined as the temperature of which the bar has only $50 \%$ of the original tensile strength. In North America, this temperature corresponds to $593^{\circ} \mathrm{C}\left(1099^{\circ} \mathrm{F}\right)$ [Bisby \& Kodur, 2007; Weber, 2008]. In the case of GFRP strength, stiffness and bond properties may reduce at temperatures above gas transition around $110^{\circ} \mathrm{C}\left(230^{\circ} \mathrm{F}\right)$ [Bisby \& Kodur, 2007]. Typically, concrete is a thermal isolator for the reinforcement, where a minimum concrete clear cover (i.e. the distance from the edge of the concrete to bar surface) is required to ensure that the rebar temperature stays within the acceptable range without experiencing severe degradation. Different values ranging from 30-70 mm (1.18-2.75 in) have been suggested [Abbasi \& Hogg 2006]. While material property changes due to the elevated temperature for steel rebars is well studied, additional research is needed for GFRP bars. In particular, changes in structural and material properties after fire exposure, since no information is available on the residual strength post-fire exposure of GFRP-RC elements materials.

The purpose of this study is to evaluate the residual mechanical properties of composite rebars extracted from structural GFRP-RC slabs post furnace fire exposure. One-way slabs reinforced with two types of commercially available GFRP bars are studied by exposing GFRP-RC slabs to a simultaneous service load and standard fire temperature profile according to ASTM E119 (Standard Test Methods for Fire Tests of Building Construction and Materials.). Post-fire exposure, the slabs were statically tested to failure at ambient temperature to determine the residual capacity. Concrete samples and GFRP rebar segments were extracted after the tests to further evaluate critical factors governing the residual properties compared to pristine rebars [Kodur and Agrawal 2015] including i) transverse shear strength according to ASTM D7617 (Standard Test Method for Transverse Shear Strength of Fiber-reinforced Polymer Matrix Composite Bars); ii) horizontal interlaminar shear strength according to ASTM D4475 (Apparent Horizontal Shear Strength of Pultruded Reinforced Plastic Rods by the Short-Beam Method); iii) glass transition temperature using Dynamic Mechanical Analysis (DMA) according to ASTM E1640 (Standard Test Method for Assignment of the Glass Transition Temperature $\left(T_{g}\right)$ by Dynamic Mechanical Analysis); and iv) change in GFRPconcrete interface using Scanning Electron Microscopy (SEM) to analyze possible microstructural degradation in GFRP bars or loss of interfacial bond.

\section{FIRE EXPOSURE AND LOAD TESTS}

Specimen Configuration. Two GFRP bars with equivalent size, with distinct surface characteristics, were selected for the slabs in this study, namely GFRP-A and GFRP-C corresponding to a fine sand coated with helically wrapped fibers; and surface lugs or ribs, similar to steel rebars, respectively. A total of $12 \mathrm{RC}$-slab specimen tests were performed: six control (benchmark) slabs, and six exposed to fire furnace and later retested at laboratory ambient conditions. Specimens are identified using the format of XYZ-\#, where X refers to RC element type (S for slabs); Y stands for the type of internal GFRP rebar (A for GFRP-A or C for GFRP-C); $\mathrm{Z}$ refers to exposure ( $\mathrm{U}$ for control and $\mathrm{F}$ for fire-exposed slabs); and \# refers to specimen repetition (1 to 3 ), as referenced in Table 1 . Additionally, Table 1 includes the nominal area, based on a circle with nominal diameter of $12.7 \mathrm{~mm}$ ( $0.5 \mathrm{in}$.), i.e. No. 4 bar classification for steel rebars; and the measured area computed according to ASTM D792 (Standard Test Methods for Density and Specific 
Gravity \{Relative Density \} of Plastics by Displacement), [Claure, et al., 2015]. GFRP-RC slabs were designed with a single GFRP bar located at the center with $19 \mathrm{~mm}(0.75 \mathrm{in}$.) of clear concrete cover, corresponding to minimum cover per design requirements. All structural elements were monolithically cast from a single batch, with normal weight concrete consisting of type I cement, with a maximum aggregate size of $6.4 \mathrm{~mm}$ (0.25 in.), and an average 28-day compressive concrete strength of $42.3 \mathrm{MPa}$ (6135 psi) according to ASTM C39 (Standard Test Method for Compressive Strength of Cylindrical Concrete Specimens). Figure 1 illustrates the slab geometry, load configuration used for both fire test and post-fire static test at ambient conditions, and the location of the GFRP reinforcement. The theoretical design capacity of the GFRP-RC slabs was according to ACI 440.1R (Guide for the Design and Construction of Structural Concrete Reinforced with FRP bars) with a strength reduction factor $(\varphi=0.55)$ for tensioncontrolled limit state and environmental reduction factor of $\left(C_{E}=0.8\right)$. The slabs were designed so that failure was controlled by rupture of the GFRP bars (under reinforced). Internal type-K thermocouples were installed at mid-span to measure the maximum temperature of the reinforcement and concrete during the test.

Table 1. Test Matrix for RC Slabs and GFRP Cross-Sectional Areas

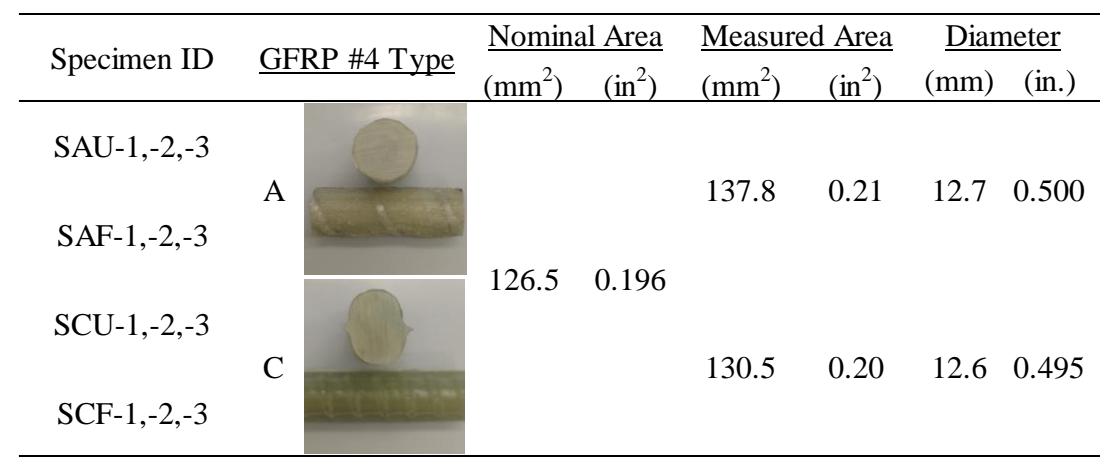
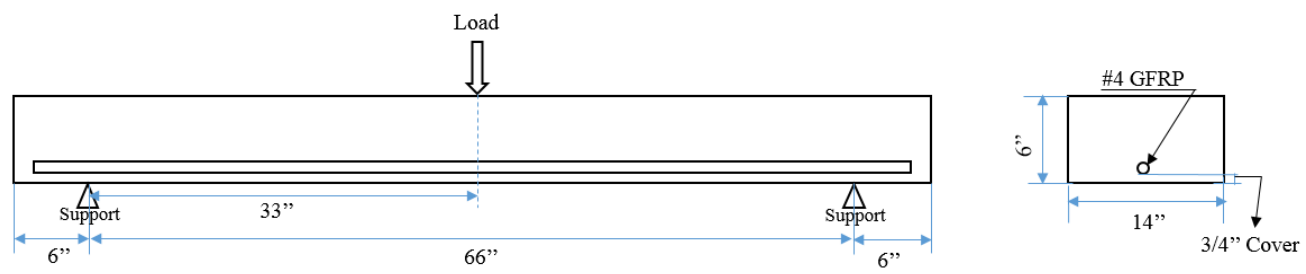

Figure 1. Schematic of GFRP-RC Slab (Note: 1 in=25.4 mm)

Furnace Fire Exposure Test. RC slabs were placed side by side vertically at the furnace opening, with the flexural side of the slabs facing the furnace, held on a steel frame providing simple support conditions and tested simultaneously for two hours per ASTM E119. A rigid deep steel spreader beam was used to equally distribute the load from a hydraulic jack to each slab independently, resulting in service point load $\left(P_{s e r}\right)$ at mid-span equivalent to $5.78 \mathrm{kN}(1300 \mathrm{lbs})$ per slab, applied simultaneous during the furnace fire exposure. Load cells and pressure gauges were used to verify and maintain the load during the fire test as illustrated in Figure 2. The gaps between the slabs and the steel frame were filled with flexible fire resistant insulation to ensure that any furnace gas heat and pressure was not lost. The ASTM E119 standard temperature-time curve constructed with a number of discrete points is approximated in equation (1), where $\mathrm{T}$ is the temperature in Celsius, $t$ refers to the time (hours), and $T_{0}$ corresponds to the ambient temperature $\left({ }^{\circ} \mathrm{C}\right)$. 


$$
T=750\left[1-e^{-3.79553 \sqrt{t}}\right]+170.41 \sqrt{t}+T_{0}
$$
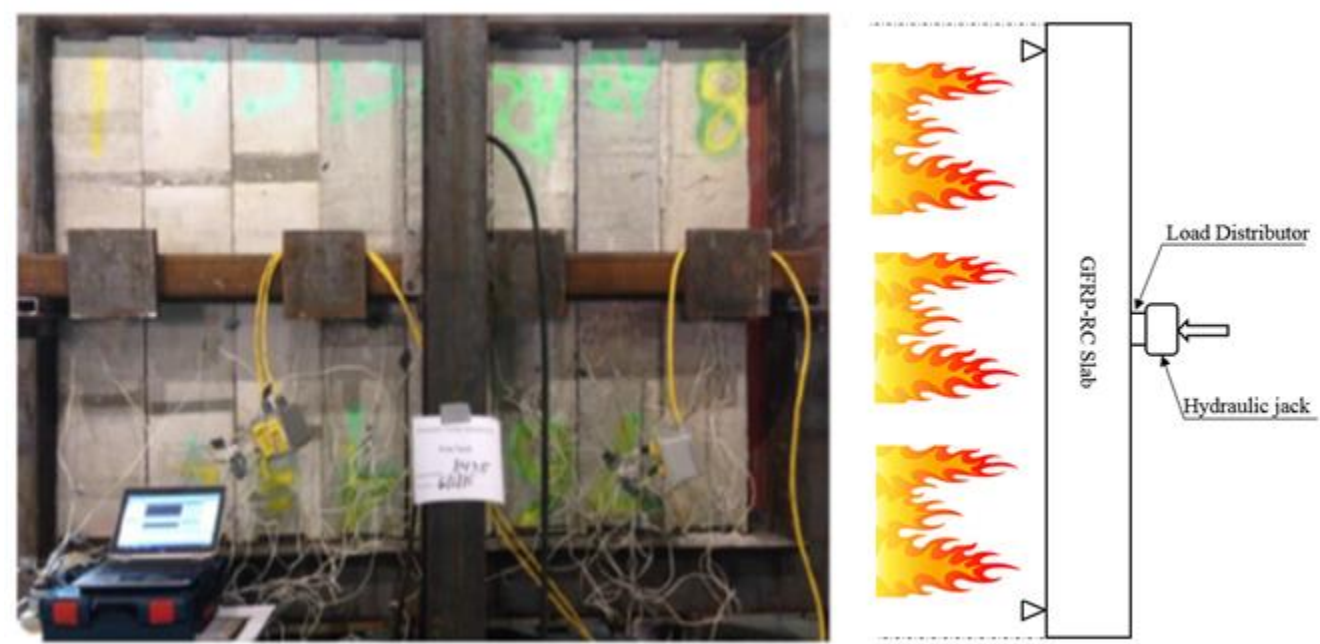

Figure 2. GFRP-RC Slabs during the Furnace Fire Test

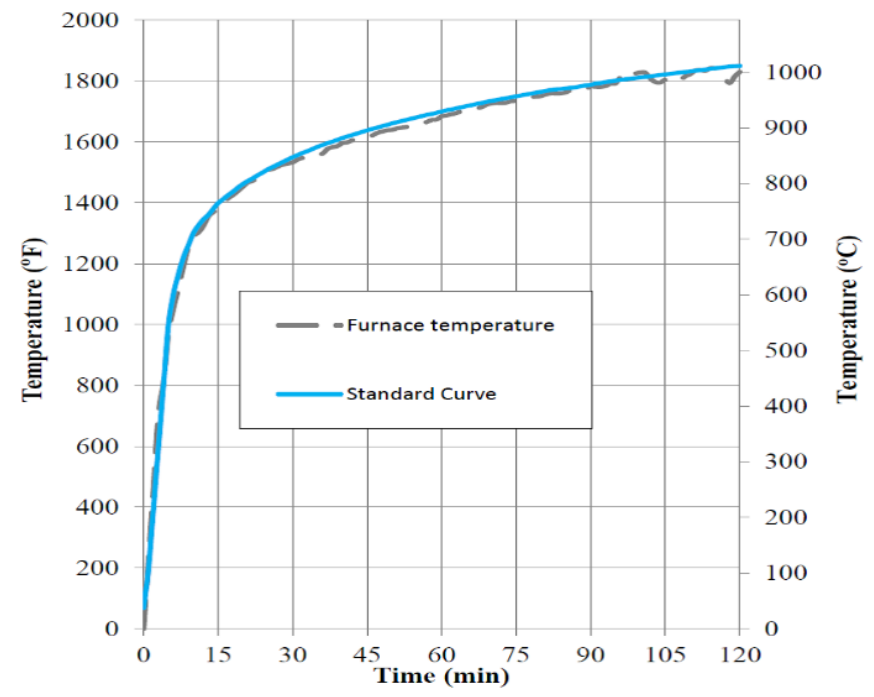

Figure 3. Temperature Profile of the Furnace

The actual furnace temperature-time curve was measured during the test using the average value of the temperature readings from nine shielded furnace thermocouples, distributed evenly inside the furnace. This was matched when compared to the standard curve profile, as seen in Figure 3. The maximum average internal temperature reached by the GFRP reinforcement at 2 hours was $115^{\circ} \mathrm{C}\left(240^{\circ} \mathrm{F}\right)$, which is within the range of $T_{g}$ temperature of the bars when softening initiates. While it is inferred that at $76 \mathrm{~mm}$ (3.0 in.) from the exposed face, the temperature within the concrete was not higher than $75^{\circ} \mathrm{C}\left(167^{\circ} \mathrm{F}\right)$ [Claure, et al., 2015]. 
Slab Residual Strength. The control and fire-exposed slabs were tested in a three-point bending configuration at ambient temperature, were the fire exposed slabs were allowed to condition for a period of 7 days prior the static test. Testing was performed using a hydraulic MTS universal test frame under displacement control until failure. During testing, the applied load, the mid-span deflection, and settlements at the supports were recorded. The load test configuration is presented in Figure 4 where a representative fire-exposed slab is shown during testing and the failure mode [Claure, et al., 2015].
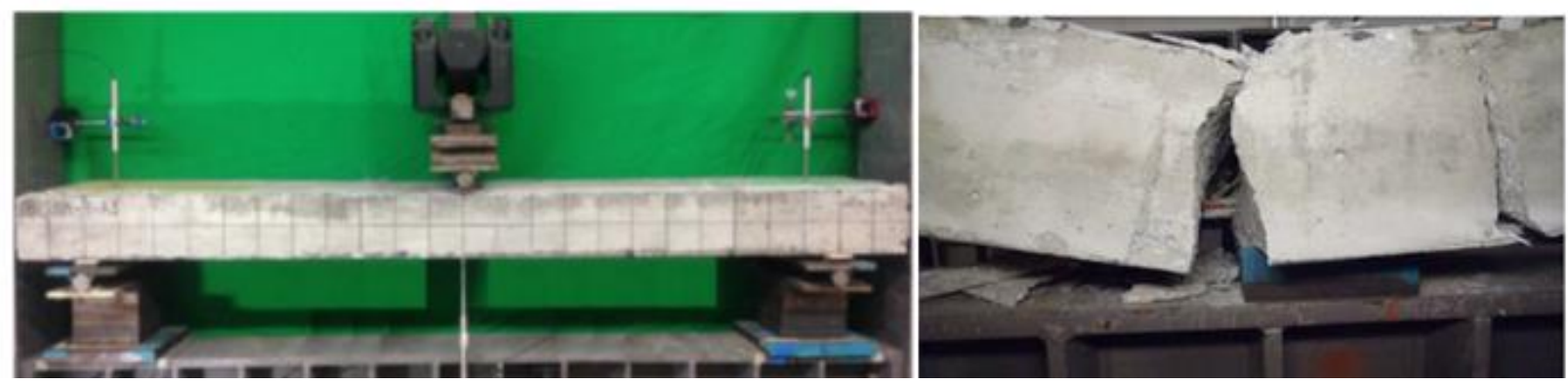

Figure 4. Fire-exposed Slab during Static Test and Failure Mode

Average ultimate load capacity results of control and fire-exposed slabs are summarized in Table 2, including ultimate experimental load $\left(P_{u \text {-exp }}\right)$, theoretical capacity $\left(P_{t h}\right)$ which does not include safety factors $\left(\varphi, C_{E}\right)$, and design capacity $\left(P_{D e s}\right)$, which includes $\varphi$ and $C_{E}$, based on ACI $440.1 \mathrm{R}$. The ratios between the experimental results versus the theoretical and design capacities are also provided. Furthermore, the average residual slab strength (RSS) is computed based on the ratio of the average experimental loads $\left(P_{u \text {-exp }}\right)$ between the fire-exposed slabs to that of the control slabs for each rebar. Overall, based on this results, slabs reinforced with GFRP-A rebar had an increased average peak load of $10 \%$, whereas slabs reinforced with GFRP-C rebars experienced an average decrease of $10 \%$. In any case, the load capacity exceeded the predicted values $\left(P_{t h}\right.$ and $\left.P_{D e s}\right)$. The reduction in capacity of slabs reinforced with GFRP-C may be due to the type of surface enhancement, where softening and deformation of the lugs resulted in the reduction of concrete to GFRP rebar bond. Furthermore, we can determine that the structural behavior of fire-exposed slabs is consistent with the expectations, having a constant stiffness until failure due to fact that the cracking moment was previously reached during fire test; while the benchmark slabs do have a change in stiffness after cracking at a range of 6 to $8 \mathrm{kN}$ (1.5 to $1.8 \mathrm{kips})$, matching the stiffness of the fire-exposed slabs, as seen in the load vs mid-span deflection diagram in Figure 5, for representative slabs.

Table 2. Post-fire Load Bearing Capacity of GFRP RC Slabs

\begin{tabular}{|c|c|c|c|c|c|c|c|c|c|c|}
\hline \multirow{2}{*}{$\begin{array}{l}\text { Slab } \\
\text { Type }\end{array}$} & \multicolumn{3}{|c|}{$P_{u \_ \text {exp }}$} & \multicolumn{2}{|c|}{$P_{t h}$} & \multicolumn{2}{|c|}{$P_{D e s}$} & \multirow[t]{2}{*}{$P_{u_{-} \exp } / P_{t h}$} & \multirow[t]{2}{*}{$P_{u_{\text {_exp }}} / P_{\text {Des }}$} & \multirow[t]{2}{*}{ RSS } \\
\hline & $(\mathrm{kN})$ & (kip) & $\operatorname{Cov}(\%)$ & $(\mathrm{kN})$ & (kip) & $(\mathrm{kN})$ & (kip) & & & \\
\hline SAU & 22.07 & 4.96 & 3.8 & 19.71 & 4.43 & 8.59 & 1.93 & 1.12 & 2.57 & 1.10 \\
\hline SAF & 24.24 & 5.45 & 2.1 & & & & & 1.23 & 2.82 & \\
\hline SCU & 21.92 & 4.93 & 3.7 & & & & & 1.11 & 2.55 & 0.90 \\
\hline SCF & 19.74 & 4.44 & 4.4 & & & & & 1.00 & 2.30 & \\
\hline
\end{tabular}




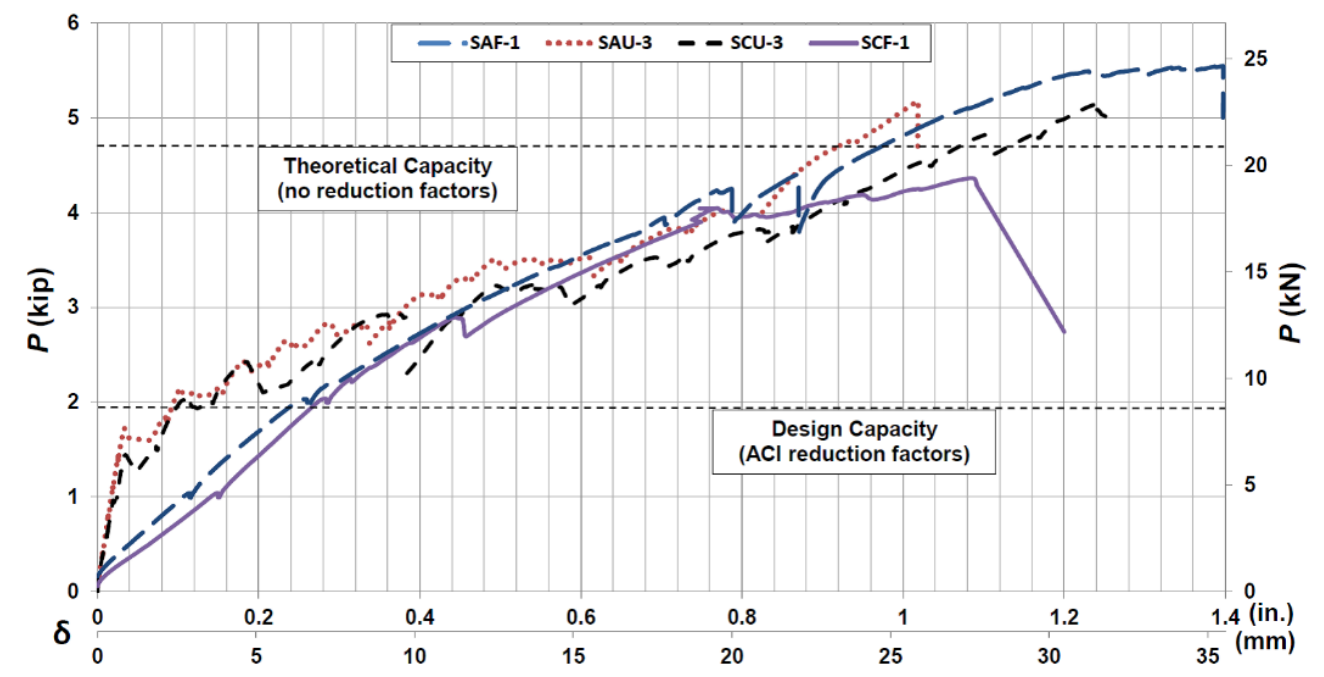

Figure 5. Load vs Mid-span Deflection for Control and Fire Exposed Slabs

\section{RESIDUAL MECHANICAL PROPERTIES OF GFRP BARS}

Transverse Shear Strength. The shear strength tests on extracted GFRP rebars from fire exposed slabs was conducted in accordance with ASTM D7617. This parameter was tested since it provides an overall mechanical performance of the composite rebar system. Three samples with a length of $230 \mathrm{~mm}(9 \mathrm{in}$.) per fire exposed slab were conducted using a universal screw driven test frame as seen in Figure 6. The load was applied at a rate of $1.27 \mathrm{~mm} / \mathrm{min}(0.05 \mathrm{in} / \mathrm{mm})$. The results were compared on tests performed on five pristine samples for each GFRP rebar type. Table 3 presents the average summary results and coefficient of variance (Cov), where $\tau^{\mathrm{T}}{ }_{\mathrm{P}}$ refers to the average transverse shear strength of the pristine rebars, and $\tau^{\mathrm{T}} \mathrm{F}$ corresponds to the average transverse shear strength of the fire exposed samples. Overall, GFRP-A and GFRP-C experienced a reduction of 5\% and $11 \%$ in shear strength, respectively. In any case, the transverse shear was always higher than the minimum accepted value of $152 \mathrm{MPa}(22 \mathrm{ksi})$. Hence, it can be deduced that after 120-minutes of furnace fire exposure, the transverse shear strength of the rebars is not affected significantly, maintaining an acceptable level of residual strength compared to pristine bars. It is noted that the ratio of GFRP-C in comparison to GFRP-A experiences a significantly higher reduction of shear strength, approximately $50 \%$

Table 3. Average Transverse Shear Test Results

\begin{tabular}{|c|c|c|c|c|c|c|c|}
\hline \multirow{2}{*}{ Rebar Type } & \multicolumn{3}{|c|}{ Average $\tau^{\mathrm{T}}{ }_{\mathrm{P}}$} & \multicolumn{3}{c|}{ Average $\tau_{\mathrm{F}}^{\mathrm{T}}$} & \multirow{2}{*}{ Ratio $\left(\tau_{F}^{T} / \tau_{P}^{T}\right)$} \\
\cline { 2 - 7 } & $(\mathrm{MPa})$ & $(\mathrm{ksi})$ & Cov $(\%)$ & $(\mathrm{MPa})$ & $(\mathrm{ksi})$ & Cov $(\%)$ & \\
\hline GFRP-A & 167.40 & 24.28 & 3.39 & 158.78 & 23.03 & 2.52 & $\mathbf{0 . 9 5}$ \\
\hline GFRP-C & 194.36 & 28.19 & 4.61 & 173.40 & 25.15 & 4.42 & $\mathbf{0 . 8 9}$ \\
\hline
\end{tabular}

Horizontal Interlaminar Shear Strength. The horizontal interlaminar shear strength determined by short-beam method was experimentally determined following the ASTM D4475, since this parameter can provide resin-fiber interphase mechanical properties, and can be a useful parameter for quality control purposes. The test span followed the standard at three times that of rebar diameter. Three samples per fire exposed slab and five samples of pristine (unexposed) GFRP rebars with the length of $50.8 \mathrm{~mm}$ (2.0 in.) for 
each bar type were tested as shown in Figure 6. Loading was applied at a rate of $1.27 \mathrm{~mm} / \mathrm{min}(0.05 \mathrm{in} / \mathrm{mm})$. Table 4 reports the average results, where $\tau^{\mathrm{H}_{\mathrm{P}}}$ refers to the horizontal shear strength of the pristine bar, and $\tau^{\mathrm{H}}{ }_{\mathrm{F}}$ refers to the horizontal shear strength of fire exposed samples. Based on the results, after 120-minutes of fire exposure, the interlaminar shear strength of both GFRP rebars have increased $15 \%$ and $7 \%$ for GFRPA and GFRP-C, respectively. This outcome provides critical information on the resin performance, which is the primary mechanism for interlaminar shear transfer. It may be reasonable to assume that the furnace fire temperature provided additional curing of the resin, resulting in an increased interlaminar shear strength of the bars. It is also noted, that the difference between both GFRP rebars is of approximately $50 \%$, as previously experienced in the transverse shear results. Currently, no values have been suggested for the minimum requirement of the horizontal interlaminar shear strength of GFRP rebars.

\section{Table 4. Average Results of the Short-beam Shear Tests}

\begin{tabular}{|c|c|c|c|c|c|c|c|}
\hline \multirow{2}{*}{ Rebar Type } & \multicolumn{3}{|c|}{ Average $\tau^{\mathrm{H}_{\mathrm{P}}}$} & \multicolumn{3}{|c|}{ Average $\tau_{\mathrm{F}}$} & \multirow{2}{*}{ Ratio $\left(\tau_{F}^{T} / \tau_{P}^{T}\right)$} \\
\cline { 2 - 7 } & $(\mathrm{MPa})$ & $(\mathrm{ksi})$ & Cov $(\%)$ & $(\mathrm{MPa})$ & $(\mathrm{ksi})$ & Cov $(\%)$ & \\
\hline GFRP-A & 49.02 & 7.11 & 2.44 & 56.67 & 8.22 & 4.95 & $\mathbf{1 . 1 5}$ \\
\hline GFRP-C & 62.53 & 9.07 & 5.67 & 67.02 & 9.72 & 1.09 & $\mathbf{1 . 0 7}$ \\
\hline
\end{tabular}
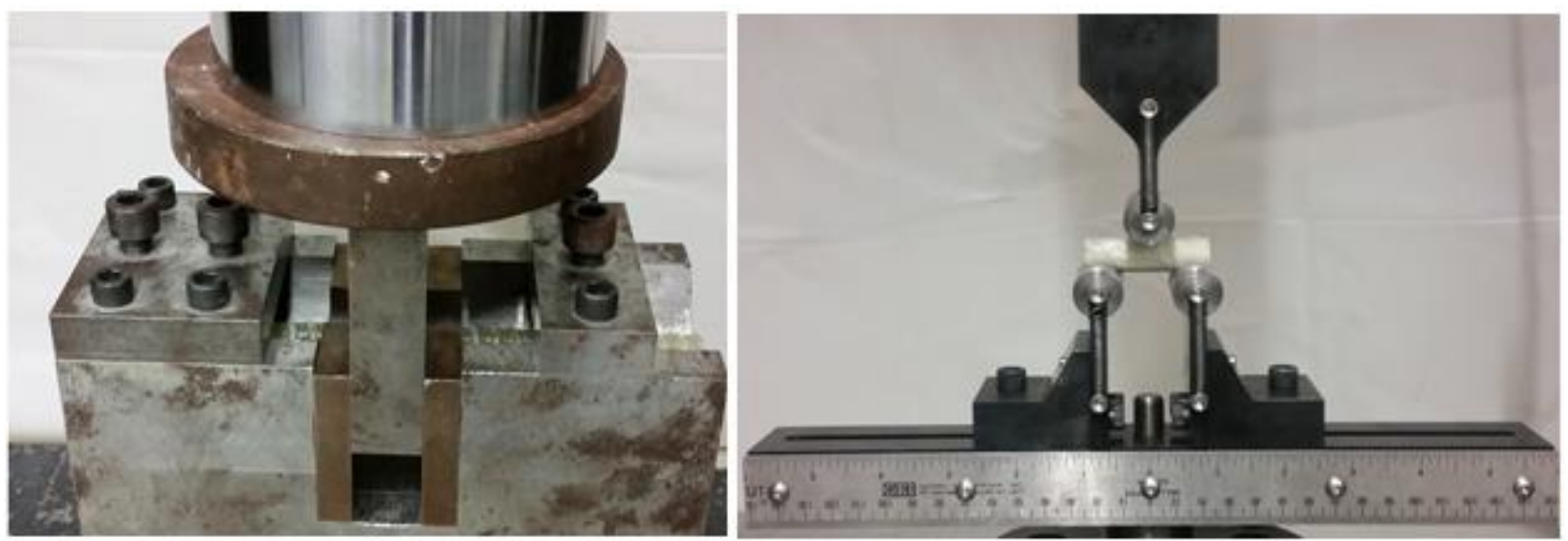

Figure 6. GFRP Bars Tested in Transverse Shear (left) and Short Beam Horizontal Shear (right)

Transition Glass Temperature. Glass transmission temperature, $T_{g}$, in polymers, is determined as it can provide resin specific properties and was measured performing dynamic mechanical analysis (DMA) test on three specimens per fire exposed slab and five samples of pristine (unexposed) GFRP rebars. The $\mathrm{T}_{\mathrm{g}}$ generally varies from rebar to rebar due to the manufacturing process and curing protocol used, but it is desired to be higher than $100^{\circ} \mathrm{C}\left(212^{\circ} \mathrm{F}\right)$. The rectangular $\mathrm{T}_{\mathrm{g}}$ specimens were extracted from the outer core of the rebars and measured $1 \times 5 \times 50 \mathrm{~mm}(0.04 \times 0.2 \times 2.0$ in.) according to ASTM E1640. The DMA test was performed with a three-point-bending fixture for a temperature ranging from $35^{\circ} \mathrm{C}\left(95^{\circ} \mathrm{F}\right)$ to $150^{\circ} \mathrm{C}$ $\left(302^{\circ} \mathrm{F}\right)$, and a heating rate of $1^{\circ} \mathrm{C} / \mathrm{min}\left(1.8^{\circ} \mathrm{F} / \mathrm{min}\right)$. Table 5 shows the average summary results, where $\mathrm{T}_{\mathrm{g}}{ }^{\mathrm{F}}$ refers to glass transition temperature of the fire exposed rebars and $\mathrm{T}_{\mathrm{g}}^{\mathrm{P}}$ corresponds to the transition glass temperature of the pristine GFRP bars. The $\mathrm{T}_{\mathrm{g}}$ for both rebars increased $47 \%$ and $25 \%$ after the fire exposure, for to GFRP-A and GFRP-C, respectively. Once again the difference in the ratio between bars is approximately $50 \%$. 
Table.5 Average Transition Glass Temperature Results

\begin{tabular}{|c|c|c|c|c|c|c|c|}
\hline \multirow{2}{*}{ Rebar Type } & \multicolumn{3}{|c|}{ Average $\mathrm{T}_{\mathrm{g}}^{\mathrm{P}}$} & \multicolumn{3}{c|}{ Average $\mathrm{T}_{\mathrm{g}} \mathrm{R}$} & \multirow{2}{*}{ Ratio $\left(T_{g}^{F} / T_{g}^{P}\right)$} \\
\cline { 2 - 7 } & $\left({ }^{\circ} \mathrm{C}\right)$ & $\left({ }^{\circ} \mathrm{F}\right)$ & $\operatorname{Cov}(\%)$ & $\left({ }^{\circ} \mathrm{C}\right)$ & $\left({ }^{\circ} \mathrm{F}\right)$ & $\mathrm{Cov}(\%)$ & \\
\hline GFRP-A & 81.1 & 177.9 & 16.6 & 119.3 & 246.7 & 5.9 & $\mathbf{1 . 4 7}$ \\
\hline GFRP-C & 107.0 & 224.6 & 7.9 & 133.5 & 272.3 & 1.9 & $\mathbf{1 . 2 5}$ \\
\hline
\end{tabular}

Scanning Electron Microscopy Imaging. Microscopic examination allows to visually detect possible damages at the single fiber scale while capturing physical degradation in the fibers, matrix or concrete-rebar interface. GFRP samples were cut in approximate thickness of $7.0 \mathrm{~mm}(0.27$ in.). The rebar specimen surfaces were prepared by sanding using different level grits (level 180, 300, $600 \& 1200)$ and employing dedicated grinding \& polishing equipment; a fine polishing completed the specimen preparation using a wet-polishing agent. Prior imaging, specimens were placed in an oven at $60^{\circ} \mathrm{C}\left(140{ }^{\circ} \mathrm{F}\right)$ for $24 \mathrm{hrs}$. to remove moisture produced during polishing procedure. Since GFRP bars are non-conductive materials, an ion sputtering device was used to coat the samples with gold prior to SEM examination. After visually analyzing numerous specimens, GFRP samples did not show any microstructure degradation after fire exposure and no damage was observed in the matrix nor resin-fiber interfaces. Since, bond degradation between concrete and reinforcement plays a critical role in fire behavior of the structure, concrete-GFRP interface were also examined, and no apparent damage or degradation was observed. SEM was performed at different magnification levels, where representative images are presented in Figure 7.
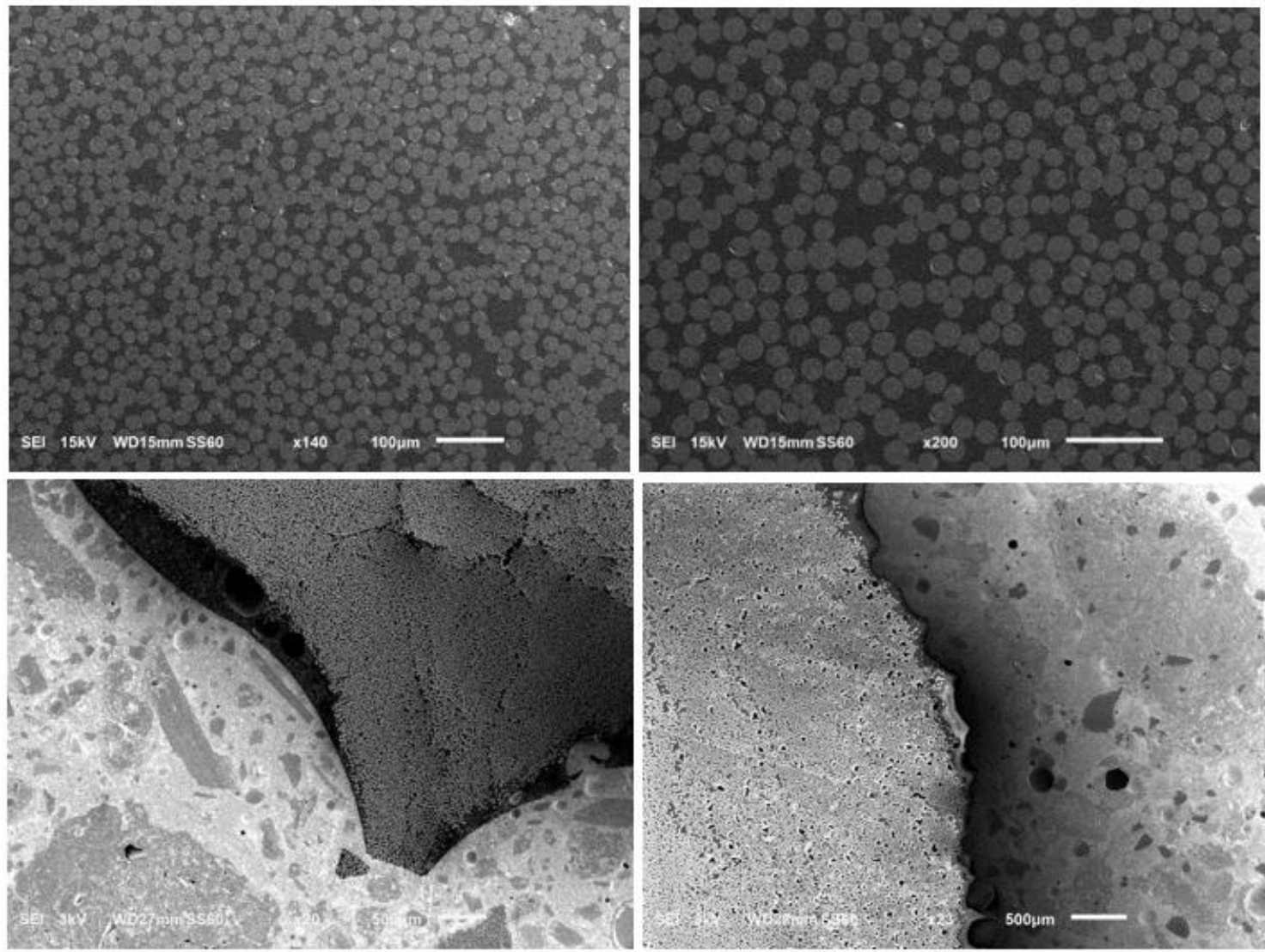

Figure 7. SEM Images of GFRP-C (left-top), GFRP-A (right-top), Concrete-Rebar Interface: GFRP-C (left-bottom) and GFRP-A (right-bottom) 


\section{CONCLUSION}

The residual strength of structural GFRP-RC slabs and rebars after 120-minute of standard fire exposure per ASTM E119 with an applied service load is presented herein to evaluate the residual mechanical properties of composite rebars extracted from the furnace fire exposed slabs. Two type of GFRP rebars with different surface characteristics were investigated: once sand coated with a helical wrap; and the other with deformed lugs. Rebar segments were extracted after the tests to evaluate critical factors governing the residual properties of GFRP bars including i) transverse shear strength; ii) horizontal interlaminar shear strength; iii) glass transition temperature, and iv) change in the GFRP-concrete interface using Scanning Electron Microscopy (SEM). The results from the two-hour furnace fire exposed specimens were compared to pristine bars, unexposed to fire. Based on the results reported, the following can be concluded:

- The residual load capacity based on three-point bending set-up of a GFRP-RC slab after conditioning to ambient temperature does not degrade the structural slab capacity below required theoretical design values based on ACI 440.1R.

- The surface characteristic a GFRP rebar can have a detrimental or beneficial impact on the performance of a GFRP-RC slab.

- The transverse shear strength of fire exposed GFRP bars was reduced but not significantly, providing a shear strength magnitude higher than the minimum required levels per design purposes.

- The horizontal shear strength of fire exposed GFRP bars increased compared to the property, signifying that the resin properties may have improved after the furnace fire exposure.

- Glass transition temperature of the bars also increased, corroborating the results from the horizontal shear strength, and signifying that the resin properties improve after a two-hour furnace fire test.

- Microscopic examination using SEM imaging did not show microstructural degradation caused by the furnace fire within the GFRP bars or at the interfacial bond in GFRP-concrete interface.

- The differences between the ratios in the results between the rebars GFRP-A and GFRP-C was consistently similar, at bout $50 \%$, which may signify that manufacturing processes are critical to the performance of a GFRP rebar both under control conditions but also after a fire exposure.

The results presented in this paper provide a general evidence that GFRP-RC elements, could be utilized in structures with possible fire scenarios as they are able to maintain the integrity of the structure for an adequate period of time. Further mechanical and material tests will be conducted to confirm the findings presented in this paper.

\section{ACKNOWLEDGMENT}

The authors gratefully acknowledge the National Science Foundation (NSF) and its industrial members for the support provided to the Industry/University Center for Integration of Composites into Infrastructure (CICI) at the University of Miami under grant NSF IIP-1439543.

\section{REFERENCES}

Abbasi, A., Hogg, P.J, (2006) "Fire Testing of Concrete Beams with Fiber Reinforced Plastic Rebar." Composites Part A; no.37:1142-50

Bisby, L.A., Kodur, V.K.R., (2007), "Evaluating the Fire Endurance of Concrete Slabs Reinforced with FRP Bars: Considerations for a holistic approach.” Composite: Part B, no.38 547-558

Claure, G., De Caso y Basalo, F. J. and Nanni, A., 2015. "Post-Fire Residual Strength of GFRP Reinforced Concrete Slabs." Proceedings of the $7^{\text {th }}$ Biennial Conference on Advanced Composites in Construction, ACIC 2015, Cambridge, UK, September 9-11, 2015, 96-104. 
CSA S806-12, (2012), "Design and Construction of Building Structures with fiber reinforced polymers"

Kodur, V.K.R, Agrawal, A., (2015), "Critical Factors Governing the Residual Response of Reinforced Concrete Beams Exposed to Fire", Fire Technologies.

Kodur, V.K.R, Bisby, L.A., Foo, S., (2005), "Thermal Behavior of Fire-Exposed Concrete Slabs Reinforced with Fiber Reinforced Polymer Bars." ACI Structure Journal, 102(6) 799-808.

Kodur, V.K.R., Baingo, D., (1998), "Fire Resistance of FRP-Reinforced Concrete Slabs.” Internal Report Institute for Research in Construction, National Research Council Canada; No.178

Nanni, A., De Luca, A., Jawaheri Zadeh, H., (2014), "Reinforced Concrete with FRP Bars", CRC Press.

Weber, A., (2008), "Fire-resistance tests on composite rebars." In: Proceedings of CICE2008, Zurich, Switzerland

Nigro E., Cefarelli G., Bilotta A., Manfredi G. and Cosenza E., (2011) "Fire Resistance of Concrete Slabs Reinforced with FRP Bars. Part I: Experimental Investigations on the Mechanical Behavior." ELSEVIER Composites Journal, 2011.02.025. 